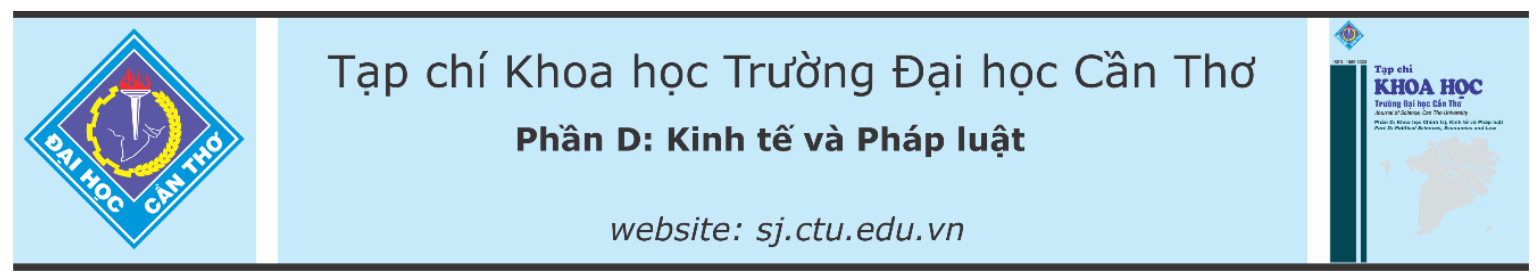

DOI:10.22144/ctu.jvn.2021.133

\title{
TÁC ĐộNG CỦA SỰ HẤP DẪN CỦA ĐIỂM ĐẾN VÀ SỬ HÀI LÒNG VỚI ĐIỂM ĐẾN TỚI HÀNH VI CÓ TRÁCH NHIÊMM VỚI MÔI TRƯ ỜNG CỦA KHÁCH DU LỊCH: TRƯỜNG HỘP TẠI THÀNH PHỐ ĐÀ NÃ̃NG
}

\author{
Nguyễn Thị Lộc ${ }^{*}$ \\ Truờng Đại học Su phạm, Đại học Đà Nã̃ng \\ *Ngưòi chịu trách nhiệm về bài viết: Nguyễn Thị Lộc (email: ntloc@ued.udn.vn)
}

\section{Thông tin chung:}

Ngày nhận bài: 22/03/2021

Ngày nhận bài sủa: 24/04/2021

Ngày duyệt đăng: 20/08/2021

\section{Title:}

The impact of destination attractiveness and place satisfaction on tourists' environmentally responsible behavior: A case study of Da Nang city

\section{Tù khóa:}

Hành vi có trách nhiệm với môi truò̀ng, khách du lịch, sư hài lòng với điểm đến, sụ hấp dẫn của điểm đến, thành phô Đà Nẵng

\section{Keywords:}

Da Nang city, destination attractiveness, environmentally responsible behavior, place satisfaction, tourist

\begin{abstract}
This study is aimed to analyze the impact of destination attractiveness and place satisfaction on tourists' environmentally responsible behavior in Da Nang city. Based on survey data of 393 tourists, the methods of exploratory factor analysis, confirmatory factor analysis, and structural equation modeling are used. The results showed that the attractiveness of the destination's core attributes and augmented attributes has positively impacted on place satisfaction and driving tourists' responsible behavior in Da Nang city. The research contributes to helping local managers understand the factors affecting tourists' environmentally responsible behavior, thereby proposing strategies to improve tourists' environmentally responsible behavior when they visit the city.
\end{abstract}

\section{TÓM TẮT}

Nghiên cứu này được thực hiện với mục tiêu phân tích tác động của sự hấp dẫn của điểm đến và sụ hài lòng với điểm đến tới hành vi có trách nhiệm với môi truờng của khách du lịch tại thành phố Đà Nã̃ng. Dựa trên dĩ liệu khảo sát 393 khách du lịch, các phuoong pháp phân tích nhân tố khám phá, nhân tố khẳng định và mô hình cấu trúc tuyến tính được sư dụng. Kết quả cho thấy sự hấp dẫn của các thuộc tính cốt lõi và thuộc tính tăng cường của điểm đến tác động tích cực tới sụ hài lòng với điểm đến và tù đó, thúc đẩy hành vi có trách nhiệm của ho tại điểm đến Đà Nã̃ng. Nghiên cứu góp phần giúp những nhà quản lý hiểu về nhân tố ảnh huơong đến hành vi có trách nhiềm với môi truờng của du khách tại đây, tù đó, có nhũng chiến lược nhằm nâng cao hành vi có trách nhiệm với môi truờng khi họ viếng thăm thành phố.

\section{GIỚI THIỆU}

Du lịch được xem là ngành kinh tế quan trọng đối với các quốc gia. Du lịch trở thành ngành kinh tế mũi nhọn trong việc tạo ra việc làm và thu nhập (Cholik \& Se, 2017). Bên cạnh những đóng góp tích cực vô cùng to lớn, hoạt động du lịch cũng gây ra những tác động tiêu cực lên nhiều khía cạnh khác như xã hội, kinh tế và nhất là đối với môi trường của điểm đến (Su \& Swanson, 2017). Cả hai khía cạnh tích cực và tiêu cực mà du lịch mang lại đã dẫn đến sự quan tâm về phát triển du lịch bền vững nhằm có thể đáp ứng nhu cầu của khách du lịch và khu vực lưu trú hiện tại, trong khi vẫn bảo đảm cơ hội ở tương lai (Su \& Swanson, 2017). Điều này yêu cầu việc quản lý các nguồn tài nguyên phải đáp ứng được nhu cầu kinh tế, xã hội và vẫn phải duy trì giá 
trị văn hóa, hệ thống sinh thái và đa dạng sinh học (Lyon et al., 2017).Trong đó, các bên liên quan (các chủ thể tham gia vào hoạt động du lịch), đặc biệt đối tượng khách du lịch, là chìa khóa dẫn đến sự thành công trong việc phát triển du lịch bền vững.

Trên thực tế, những hành vi có ý thức hoặc không có ý thức của du khách trong khi du lịch đã gây ra những ảnh hưởng tiêu cực cho điểm đến $\mathrm{du}$ lịch, đặc biệt ở khía cạnh môi trường ( $\mathrm{Su}$ et al., 2018). Việc giảm thiểu những tác động của du khách đến môi trường du lịch trở thành vấn đề quan trọng đối với các nhà nghiên cứu và quản trị điểm đến. Thúc đẩy hành vi có trách nhiệm với môi trường của du khách là cách hiệu quả để phát triển du lịch bền vững, bởi vì việc hình thành hành vi có trách nhiệm với môi trường sẽ quyết định đến hành vi vì môi trường cụ thể, như ý định lựa chọn điểm đến du lịch sinh thái, bảo tồn các khu vực hoang dã và ý định lựa chọn khách sạn "xanh". Do đó, việc chú trọng khuyến khích hành vi có trách nhiệm với môi trường của khách du lịch đang là vấn đề được quan tâm. Vì vậy, nghiên cứu này thực hiện có đóng góp về mặt lý thuyết trong việc xác định các nhân tố ảnh hưởng và thúc đẩy đến ý định và sự hình thành hành vi có trách nhiệm với môi trường của du khách tại các điểm đến du lịch.

Đà Nẵng là điểm đến du lịch nổi tiếng với cả du khách trong nước và quốc tế. Đà Nẵng có vị trí thuận lợi và sở hữu tiềm năng du lịch phong phú cũng như các tài nguyên du lịch có giá trị. Với những lợi thế đó, du lịch đang là ngành kinh tế quan trọng của thành phố Đà Nẵng. Bên cạnh những đóng góp tích cực thì việc phát triển du lịch cũng đem lại những tác động không mong muốn đến môi trường. Sự phát triển du lịch một cách ồ ạt, không theo quy hoạch đã gây ra ảnh hưởng nặng nề đối với môi trường tự nhiên như khai thác quá mức, sự ô nhiễm môi trường, gây sức ép đến nguồn tài nguyên của địa phương, từ đó có thể ảnh hưởng tới hình ảnh điểm đến. Chính vì vậy, thành phố Đà Nẵng đã và đang xây dựng định hướng phát triển du lịch bền vững, trong đó phải kể đến những hoạch định nhằm hạn chế những tác động tiêu cực của du lịch tới môi trường.

Nhiều nghiên cứu trong du lịch cho thấy rằng sức hấp dẫn của điểm đến là một yếu tố quan trọng chỉ dẫn về sự thu hút của khách du lịch đối với một điểm đến (Dolnicar \& Leisch, 2008; Hou et al., 2005;) và cũng chỉ ra mối tương quan giữa sự hài lòng và sự ủng hộ của môi trường (Cheng et al., 2013; Ramkissoon et al., 2012). Do vậy, để góp phần hiểu rõ hơn về các nhân tố ảnh hướng đển hành vi có trách nhiệm với môi trường của khách du lịch, nghiên cứu này được thực hiện với mục đích xem xét tác động của sự hấp dẫn của điểm đến thông qua các thuộc tính cốt lõi và thuộc tính tăng cường tới sự hài lòng và từ đó, tới hành vi có trách nhiệm với môi trường tại điểm đến Đà Nẵng.

\section{CƠ SỞ LÍ THUYẾT}

\subsection{Sự hấp dẫn của điểm đến}

Sự hấp dẫn của điểm đến là một vấn đề được quan tâm nghiên cứu từ nhiều tác giả. $\mathrm{Hu}$ and Ritchie (1993) định nghĩa sự hấp dẫn của điểm đến bao gồm tất cả những khả năng mà một điểm đến mang lại sự hài lòng và lợi ích cho khách du lịch. Theo Krešić and Prebežac (2011), sự hấp dẫn là hình ảnh tinh thần của một điểm đến, được tạo ra thông qua các điểm tham quan có sẵn ở một điểm đến. Sự hấp dẫn là nhân tố quyết định tới sự phát triển kinh tế và hoạt động du lịch (Andersson \& Getz, 2009; Sofield, 2006). Sự hấp dẫn của điểm đến gắn liền với các thuộc tính cốt lõi, tiêu biểu là các giá trị tài nguyên tự nhiên và nhân văn (Hou et al., 2005; Mohammed et al., 2018) và các thuộc tính bổ sung, như các hàng hóa, dịch vụ phục vụ cho chuyến đi (Cheng et al., 2013; Hou et al., 2005).

Sức hấp dẫn là nhân tố quan trọng đối với khách du lịch (Funk et al., 2004). Theo Benckendorff and Pearce (2003), "sự hấp dẫn" là động lực ban đầu để khách du lịch lựa chọn điểm đến theo sở thích và mục đích chuyến đi của họ. Sự hấp dẫn góp phần giúp khách du lịch đạt được các mục đích chuyến đi như giải trí, nghỉ dưỡng và giáo dục $(\mathrm{Hu} \&$ Wall, 2005; Leask, 2010). Sức hấp dẫn của một điểm đến tùy thuộc vào loại địa điểm du lịch mà du khách đến thăm (Krešić \& Prebežac, 2011) và cảm nhận của khách du lịch tại đó (Albayrak \& Caber, 2013).

\subsection{Sự hài lòng với điểm đến}

Stedman (2002) định nghĩa sự hài lòng với điểm đến là những giá trị của một địa điểm khi đáp ứng những mong đợi, nhu cầu của khách du lịch và bao gồm cả nhận thức và tình cảm thông qua trải nghiệm du lịch (Mohammed et al., 2018; Ramkissoon et al., 2012). Sự hài lòng của du khách là thang đo sự thành công của điểm đển trong việc cung cấp trải nghiệm chất lượng cao cho khách du lịch (Coghlan, 2012) và nhân tố phản ánh chất lượng dịch vụ (Lai \& Chen, 2011). Sự hài lòng tác động tích cực tới lòng trung thành (Barnes et al., 2014; Parola et al., 2014), ý định quay lại, sự truyền miệng và ý định giới thiệu về điểm đến (Hosany \& Prayag, 2013). 


\subsection{Hành vi có trách nhiệm với môi trường}

Hành vi có trách nhiệm với môi trường đề cập đến các hành động phản ánh mối quan tâm đối với môi trường tự nhiên của các cá nhân hoặc nhóm (Cheng et al., 2013). Hành vi có trách nhiệm với môi trường mang lại lợi ích và/hoặc giảm tác hại đối với môi trường tự nhiên (Steg \& Vlek, 2009). Hành vi có trách nhiệm với môi trường bao gồm mối quan tâm về môi trường, cam kết và kiến thức sinh thái (Halpenny, 2010).

Đối với khách du lịch, nhận định hành vi có trách nhiệm với môi trường đề cập đến việc nỗ lực giảm thiểu các tác động tiêu cực, bảo vệ môi trường hoặc tránh làm hỏng môi trường trong quá trình trải nghiệm du lịch của họ tại một điểm đến (He et al., 2018). Trong lĩnh vực du lịch, hành vi có trách nhiệm với môi trường của khách du lịch là chủ đề được quan tâm vì nó được coi là yếu tố chính để đảm bảo sự thành công và tính bền vững của phát triển du lịch (Lee et al., 2013).

\section{PHƯONG PHÁP NGHIÊN CÚU}

\subsection{Giả thuyết và mô hình nghiên cứu}

\subsubsection{Giả thuyết}

Barnes et al. (2014) cho rằng sự hài lòng được kích thích thông qua cảm giác tâm lý của khách du lịch về điểm đển mà họ đển thăm và mỗi điểm đến truyền tải nhiều cảm giác khác nhau tùy thuộc vào các thuộc tính của từng điểm đến. Sự tác động của các thuộc tính tới sự hài lòng của du khách tại một điểm đến đã được đề cập trong các nghiên cứu trước. Cụ thể, Romão et al. (2014) nhận định sự hài lòng của du khách có được từ sự hài lòng với các giá trị tài nguyên du lịch tự nhiên hấp dẫn của điểm đến, hay trong nghiên cứu của Cheng et al. (2013) cũng kết luận, giá trị văn hoá đặc sắc của điểm đến là nhân tố quan trọng quyết định sự hài lòng của du khách. Akama and Kieti (2003) cũng chỉ ra rằng số lượng khách du lịch giảm ở một điểm đến là vì sự không hài lòng với chất lượng sản phẩm và dịch vụ của điểm đến du lịch (thuộc tính bổ sung). Do đó, nghiên cứu đề xuất giả thuyết về mối quan hệ giữa các thuộc tính cốt lõi và thuộc tính bổ sung của điểm đến với sự hài lòng, cụ thể:

H1: Mức độ hấp dẫn của các thuộc tính cốt lõi của điểm đến có ảnh hưởng tích cực đến sự hài lòng của khách du lịch với điểm đến.

H2: Mức độ hấp dẫn của các thuộc tính bổ sung của điểm đến có ánh huởng tích cực đến sự hài lòng của khách du lịch với điểm đến.

Sự hài lòng của khách hàng là tiền đề hình thành nên các hành vi của khách hàng (Chi \& $\mathrm{Qu}, 2008$; Su \& Hsu, 2013; Su et al., 2017). Trong du lịch, sự hài lòng này sẽ tác động đến hành vi của khách du lịch đối với một điểm đến. Cụ thể, những cá nhân hài lòng với môi trường tự nhiên một cách tích cực có xu hướng tham gia vào các hành vi bảo vệ môi trường tại đó (Davis et al., 2011). Do đó, nghiên cứu đề xuất giả thuyết:

H3: Sụ hài lòng về điểm đến có ảnh hưởng tích cực đến hành vi có trách nhiệm với môi trường của khách du lịch.

\subsubsection{Mô hình nghiên cứu}

Nghiên cứu đề xuất mô hình sau:

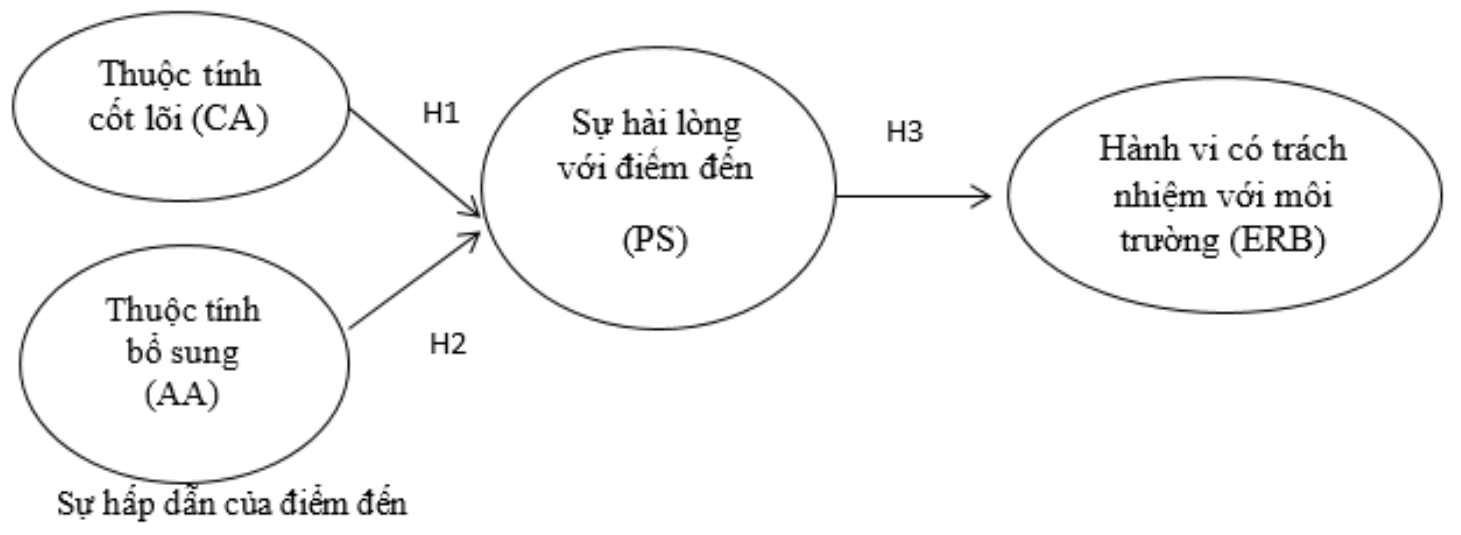

Hình 1. Mô hình nghiên cứu 


\subsection{Thiết kế bản câu hỏi và mẫu}

Bản câu hỏi có tổng số 20 câu bao gồm 15 biến quan sát của 4 thang đo đề xuất để phân tích mối quan hệ giữa sự hấp dẫn của điểm đến, sự hài lòng với điểm đến và hành vi có trách nhiệm với môi trường của khách du lịch, 5 biến liên quan tới thông tin nhân khẩu của các đáp viên và được đánh giá bằng thang Likert từ 1 đến 5 , tương ứng với các mức đánh giá từ Hoàn toàn không đồng ý (1) đến Hoàn toàn đồng ý (5).
Thang đo được xây dựng dựa trên sự kế thừa từ các nghiên cứu trước, song có sự lược bỏ và hiệu chỉnh để phù hợp với đối tượng và phạm vi nghiên cứu. Cụ thể, đối với thang đo Sự hấp dẫn của điểm đến, nghiên cứu kế thừa 4 biến quan sát cho thuộc tính cốt lõi và 4 biến quan sát cho thuộc tính bổ sung của Cheng et al. (2013). Nghiên cứu kế thừa 3 biến quan sát của Veasna et al. (2013) cho thang đo Sự hài lòng với điểm đến và 4 biến quan sát của $\mathrm{He}$ et al. (2018) cho thang đo Hành vi có trách nhiệm với môi trường của khách du lịch (Bảng 1 )

Bảng 1. Tổng họ̣p biến quan sát của các thang đo

\begin{tabular}{|c|c|c|c|c|}
\hline THANG ĐO & & Mã biến & Biến quan sát & Nguồn \\
\hline \multirow{8}{*}{$\begin{array}{l}\text { Sự hấp dẫn của } \\
\text { điểm đến }\end{array}$} & Thuộc & CA1 & Môi trường sinh thái độc đáo & \multirow{4}{*}{$\begin{array}{l}\text { Cheng et al. } \\
(2013)\end{array}$} \\
\hline & tính cốt & CA2 & Các danh thắng hấp dẫn & \\
\hline & & CA3 & Bãi biển đẹp & \\
\hline & & CA4 & Di tích lịch sử và văn hóa đặc sắc & \\
\hline & Thuộc & AA1 & Cơ sở lưu trú và ăn uống đầy đủ và tiện nghi & \multirow{4}{*}{$\begin{array}{l}\text { Cheng et al. } \\
(2013)\end{array}$} \\
\hline & tính bổ & AA2 & Giao thông thuận tiện & \\
\hline & & AA3 & $\begin{array}{l}\text { Các dịch vụ lữ hành (chương trình chuyến đi, } \\
\text { hướng dẫn viên) đảm bảo chất lượng }\end{array}$ & \\
\hline & & AA4 & Đặc sản địa phương và quà lưu niệm độc đáo & \\
\hline \multirow{3}{*}{\multicolumn{2}{|c|}{ Sự hài lòng với điểm đến }} & PS1 & $\begin{array}{l}\text { Tôi nghĩ rằng mình đã đúng khi lựa chọn viếng } \\
\text { thăm thành phố Đà Nẵng }\end{array}$ & \multirow{3}{*}{$\begin{array}{l}\text { Veasna et al. } \\
(2013)\end{array}$} \\
\hline & & PS2 & $\begin{array}{l}\text { Nhìn chung, tôi hài lòng với quyết định đến thăm } \\
\text { thành phố Đà Nẵng }\end{array}$ & \\
\hline & & PS3 & $\begin{array}{l}\text { Tôi cảm thấy hạnh phúc/thích khi viếng thăm } \\
\text { thành phố Đà Nẵng }\end{array}$ & \\
\hline \multirow{4}{*}{$\begin{array}{l}\text { Hành vi có trách } \\
\text { môi trường }\end{array}$} & & ERB1 & $\begin{array}{l}\text { Tôi tuân theo các quy định để ngăn chặn việc phá } \\
\text { hủy môi trường của thành phố Đà Nắng }\end{array}$ & \multirow{4}{*}{$\begin{array}{l}\hat{e} \\
\text { He et al. (2018) } \\
c \\
\tilde{e} \\
c\end{array}$} \\
\hline & & ERB2 & $\begin{array}{l}\text { Tôi cố gắng không làm ảnh hưởng hệ động và thực } \\
\text { vật trong chuyến du lịch của mình }\end{array}$ & \\
\hline & nhiệm với & i ERB3 & $\begin{array}{l}\text { Tôi cố gắng thuyết phục những người khác bảo vệ } \\
\text { môi trường tự nhiên }\end{array}$ & \\
\hline & & ERB4 & $\begin{array}{l}\text { Khi tôi thấy những người khác tham gia vào việc } \\
\text { hủy hoại môi trường tại thành phố Đà Nẵng, tôi sẽ } \\
\text { báo cáo với cơ quan quản lý điểm đến hoặc các } \\
\text { đơn vị có liên quan }\end{array}$ & \\
\hline
\end{tabular}

Các đáp viên trong nghiên cứu là những du khách đã và đang tới thành phố Đà Nẵng du lịch. Do tác động của dịch Covid-19, khảo sát được chia thành 2 đợt.

Đợt 1: Khảo sát trực tiếp, từ ngày 30 tháng 12 năm 2020 đến ngày 5 tháng 1 năm 2021 tại các điểm du lịch trên thành phố Đà Nẵng.

Đợt 2: Khảo sát online qua các câu hỏi được tạo trên Google Docs và được chia sẻ lên mạng xã hội Facebook từ ngày 20 tháng 1 năm 2021 đển ngày 20 tháng 2 năm 2021.
Để đảm bảo độ tin cậy khi thu thập số liệu gián tiếp qua Facebook, trong phần mô tả, bản câu hỏi trình bày rõ đối tượng tham gia khảo sát là những khách du lịch từng tới Đà Nẵng tham quan. Cuối cùng, có tồng số 393 phiếu trả lời hợp lệ được sử dụng để phân tích kết quả.

\subsection{Kĩ thuật phân tích}

Để phân tích dữ liệụ thu thập được, công cụ SPSS 20 và AMOS 24 được sử dụng. Quá trình được thực hiện theo các bước sau:

- Bước 1: Phân tích nhân tố khám phá (EFA) được thực hiện để tổng hợp biến quan sát của các 
thang đo và thực hiện kiểm tra độ tin cậy của thang đo (hệ số tin cậy Cronbach's Alpha).

- Bước 2: Các mô hình thang đo chung (measurement models) được kiểm tra bởi phân tích nhân tố khẳng định CFA.

- Bước 3: Kiểm định mô hình nghiên cứu cùng với các giả thuyết thông qua phương pháp phân tích mô hình cấu trúc tuyến tính (SEM).

\section{KẾT QUẢ VÀ THẢO LUẬn}

\subsection{Kết quả nghiên cứu}

4.1.1. Thông tin nhân khẩu của các đáp viên

Trong tổng số 393 đáp viên, phần lớn là nữ với $61,3 \%$ và chỉ có $38,7 \%$ là nam. Về độ tuổi, phần lớn

Bảng 2. Đặc điểm mẫu khảo sát

\begin{tabular}{|c|c|c|c|}
\hline Nhân tố & & Số lượng & Phần trăm (\%) \\
\hline \multirow{2}{*}{ Giới tính } & Nũ & 241 & 61,3 \\
\hline & Nam & 152 & 38,7 \\
\hline \multirow{4}{*}{ Tuổi } & Dưới 18 tuối & 11 & 2,9 \\
\hline & $18-25$ & 191 & 48,5 \\
\hline & $26-40$ & 129 & 32,7 \\
\hline & Trên 40 tuối & 62 & 15,9 \\
\hline \multirow{2}{*}{ Tình trạng hôn nhân } & Độc thân & 266 & 67,7 \\
\hline & Kết hôn & 127 & 32,3 \\
\hline \multirow{4}{*}{ Trình độ học vấn } & Dưới trung học phổ thông & 8 & 2,1 \\
\hline & Trung học phổ thông & 70 & 17,8 \\
\hline & Trung cấp/ cao đẳng/ đại học & 258 & 65,6 \\
\hline & Sau đại học & 57 & 14,5 \\
\hline \multirow{3}{*}{ Số lần viếng thăm } & Lần đầu & 276 & 70,2 \\
\hline & Lần thứ hai & 63 & 16 \\
\hline & Từ ba lần trở lên & 54 & 13,8 \\
\hline
\end{tabular}

\subsubsection{Kiểm định thang đo với phân tích nhân tố khám phá (EFA) và Cronbach's Alpha}

Phân tích nhân tố khám phá (sử dụng kĩ thuật trích yếu tố Principal Axis Factoring với phép quay Promax) được thực hiện cho toàn bộ các biến quan sát. Kết quả rút trích được 4 nhân tố tại Eigenvalue là 1,900 , tổng phương sai trích là $71,253 \%(>50 \%)$ cho thấy mô hình EFA là phù hợp, 4 nhân tố phân tích cô đọng được $77,65 \%$ biến thiên của các biến quan sát; hệ số KMO là $0,770(>0,5)$; ý nghĩa thống kê của kiểm định Bartlett với Sig. $=0,000(<0,05)$. Hệ số tải nhân tố của các biến khác đều lớn hơn 0,5 (Bảng 3) nên được giữ lại cho phân tích kế tiếp. các đáp viên có độ tuổi từ 18 đến 40 (chiếm $81,2 \%$ ), tỉ lệ trên 40 tuổi chiếm $15,9 \%$ và độ tuổi dưới 18 chiếm tỉ lệ thấp nhất (chiếm $2,9 \%$ ). Về tình trạng hôn nhân, các đáp viên độc thân chiếm $67,7 \%$ và đã kết hôn chiếm 32,3\%. Liên quan đến trình độ học vấn, kết quả cho thấy các đáp viên có trình độ trung cấp/cao đẳng/ đại học chiếm tỉ trọng cao nhất với $14,5 \%$; tốt nghiệp trung học phổ thông với tỉ lệ $17,3 \%$; và dưới trung học phổ thông chiếm $2,1 \%$. Có 276 đáp viên mới viếng thăm thành phố Đà Nẵng lần đầu tiên, 63 đáp viên là lần thứ 2 và 54 đáp viên từ 3 lần trở lên (Bảng 2). $66,1 \%$; đáp viên có trình độ sau đại học chiếm
Bảng tổng hợp kết quả phân tích Cronbach's alpha (Bảng 3) cho thấy các thang đo đều đảm bảo tính nhất quán nội tại vì có Cronbach's alpha lớn hơn 0,7. Cụ thể, Cronbach's alpha của thuộc tính cốt lõi là 0,891 , thuộc tính tăng cường là 0,833 , sự hấp dẫn của điểm đến là 0,911 và hành vi có trách nhiệm với môi trường của khách du lịch là 0,922 . Ngoài ra, các hệ số tương quan biến tổng của các biến quan sát trong từng thang đo đều cao hơn mức giới hạn 0,3 . Do đó, các biến quan sát của các thang đo được giữ cho phân tích nhân tố khẳng định. 
Bảng 3. Kết quả phân tích nhân tố (EFA) và kiểm định Cronbach's Alpha

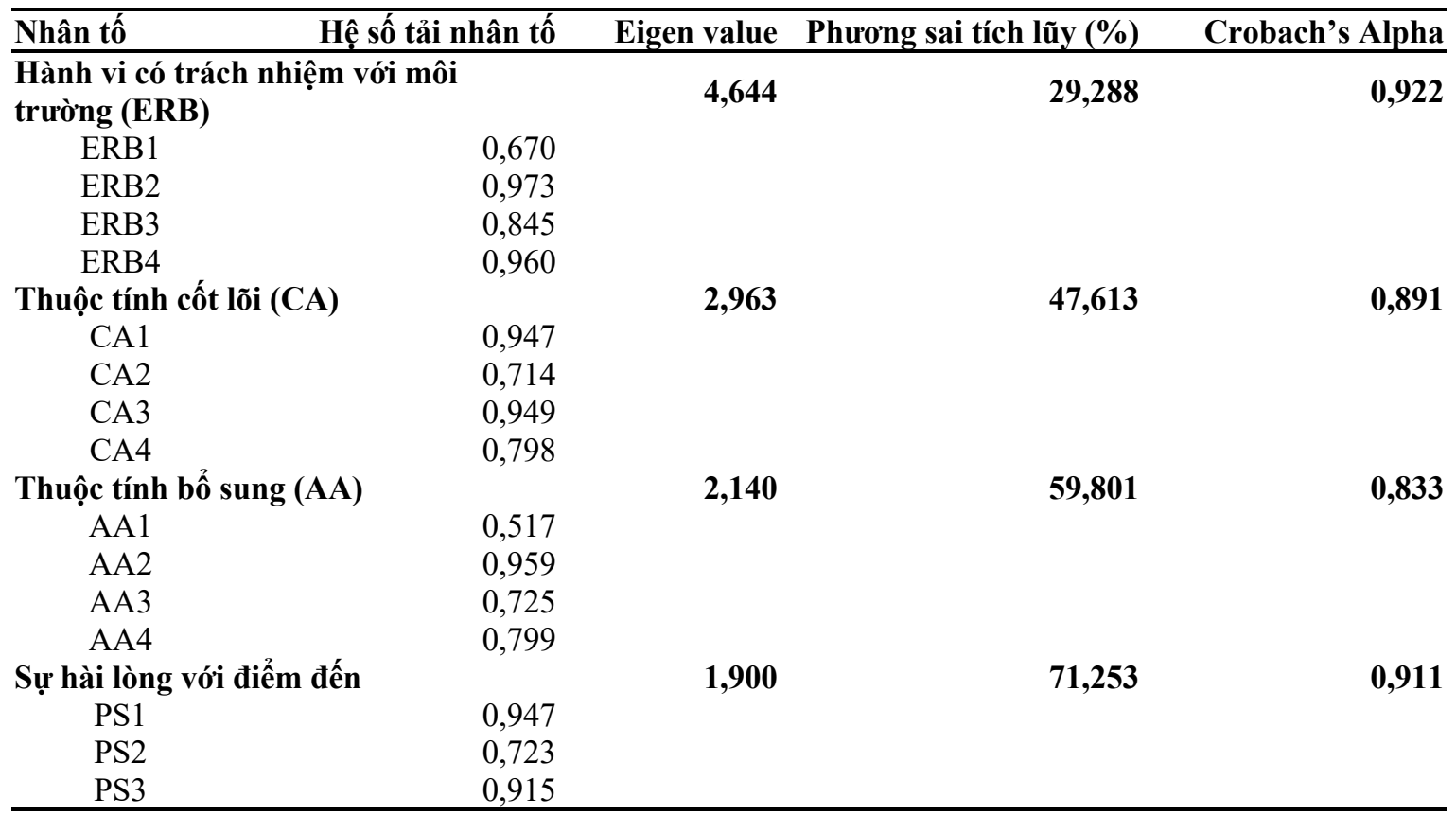

4.1.3. Kiểm định thang đo với phân tích nhân tố khẳng định (CFA)

a. Đánh giá độ phù hợp của toàn bộ mô hình

Kết quả kiểm định mô hình thang đo chung của toàn bộ mô hình thông qua CFA cho thấy mô hình có giá trị chi-bình phương tương đối theo bậc tự do $(\mathrm{cmin} / \mathrm{df}=2,931<3)$. Các chỉ tiêu đo lường mức độ phù hợp khác đều đạt yêu cầu IFI $=0,967(>0,9)$; $\mathrm{CFI}=0,966(>0,9) ; \mathrm{PNFI}=0,760(>0,5) ; \mathrm{PCFI}=$ $0,648(>0,5) ;$ RMSEA $=0,07(<0,08)$, GFI $=0,926$
$(>0,9)$ và $\mathrm{TLI}=0,958(>0,9)$. Do vậy, mô hình thang đo chung thích hợp với bộ dữ liệu thực tế.

b. Kết quả kiểm tra giá trị hội tu

Bảng 4 thể hiện kết quả kiểm tra giá trị hội tụ của 4 mô hình thang đo chung. Kết quả cho thấy độ tin cậy của các biến quan sát. Giá trị trọng số chuẩn hóa lớn hơn 0,5 ; độ tin cậy tổng hợp (CR) lớn hơn 0,7 và các khái niệm có phương sai trích trung bình lớn hơn mức đề nghị 0,5 (Bảng 3). Do vậy các biến quan sát đạt được độ tin cậy.

Bảng 4. Kết quả của kiểm tra giá trị hội tụ của các mô hình thang đo chung

\begin{tabular}{llccc}
\hline Cấu trúc & Các biến quan sát & Trọng số chuẩn hóa & CR & AVE \\
\hline \multirow{4}{*}{ CA } & CA1 & 0,933 & & \\
& CA2 & 0,688 & 0,893 & 0,684 \\
& CA3 & 0,964 & & \\
& CA4 & 0,628 & & \\
\multirow{4}{*}{ AA } & AA1 & 0,555 & 0,847 & 0,589 \\
& AA2 & 0,955 & & \\
& AA3 & 0,713 & \\
& AA4 & 0,791 & 0,917 \\
\multirow{3}{*}{ PS } & PS1 & 0,909 & & \\
& PS2 & 0,768 & \\
& PS3 & 0,893 & 0,789 \\
\multirow{5}{*}{ ERB } & ERB1 & ERB2 & 0,676 & 0,931 \\
& ERB3 & 0,961 & & \\
& ERB4 & 0,862 & \\
\hline
\end{tabular}




\section{c. Kết quả kiểm tra giá trị phân biệt}

Phương pháp AVE được áp dụng để kiểm tra giá trị phân biệt giữa các cấu trúc. Bảng 5 cho thấy những số hàng chéo thể hiện căn bậc hai của $\mathrm{AVE}$ của các thang đo. Các số thể hiện trong một ô là mối quan hệ tương quan giữa hai thang đo được dán nhãn trong hàng ngang và trong hàng dọc. Giá trị phân biệt của tất cả mối quan hệ giữa các thang đo được đảm bảo khi tất cả các giá trị căn bậc hai của $\mathrm{AVE}$ đều lớn hơn hệ số tương quan của các thang đo. Trong Bảng 5 tất cả các giá trị đáp ứng yêu cầu của kiểm định giá trị phân biệt.
Bảng 5. Kết quả kiểm tra giá trị phân biệt giữa các thang đo

\begin{tabular}{lrrrr}
\hline AVE/ R2 & CA & AA & PS & ERB \\
\hline CA & 0,827 & & & \\
AA & 0,251 & 0,767 & & \\
PS & 0,227 & 0,204 & 0,888 & \\
ERB & 0,098 & 0,116 & 0,220 & 0,881 \\
\hline
\end{tabular}

4.1.4. Kiểm định mô hình nghiên cứu và giả thuyết nghiên cưu

a. Đánh giá độ phù hợp của mô hình

Mô hình nghiên cứu đề nghị được kiểm định thông qua phân tích mô hình cấu trúc tuyến tính (SEM) với 4 mô hình cấu trúc và một ma trận tương quan gồm 15 biến quan sát (Hình 2).

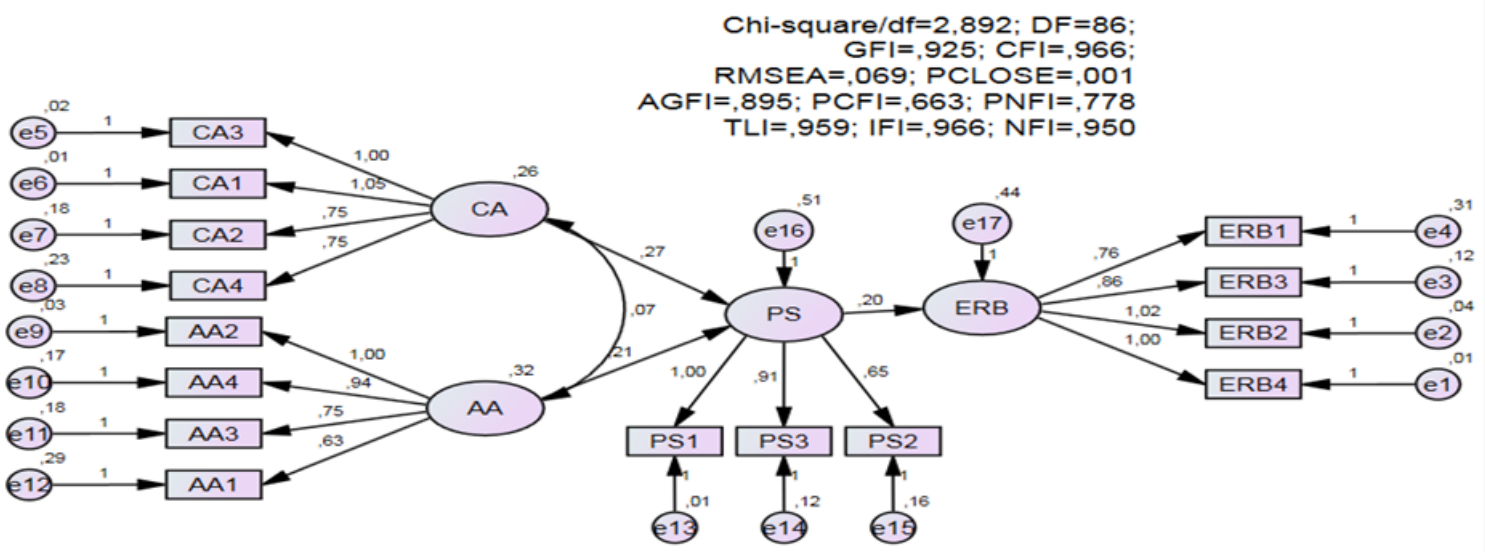

\section{Hình 2. Kết quả phân tích mô hình cấu trúc tuyến tính (SEM}

Kết quả SEM được mô tả trong Hình 2 là $\mathrm{df}=$ $86, \chi 2 / \mathrm{df}=2,892(<3), \mathrm{IFI}=0,966(>0,9), \mathrm{TLI}=$ $0,959(>0,9)$, PNFI $=0,778(>0,5)$, RMSEA $=$ $0,069(<0,08)$. Những kết quả này cho thấy sự phù hợp tốt với mô hình cấu trúc được đề xuất.

b. Kiểm tra giả thuyết nghiên cưu

Kết quả nghiên cứu cho thấy tất cả các giả thuyết đưa ra đều được chấp nhận. Cụ thể, cả thuộc tính cốt lõi và thuộc tính bổ sung đều là nhân tố tác động tới sự hài lòng với điểm đến của khách du lịch (có giá trị estimate $=0,270$ và 0,206 tương ứng, $P<0,05$ ) và sự hài lòng với điểm đến tác động tích cực đến hành vi có trách nhiệm với môi trường của du khách (có giá trị estimate $=0,202, \mathrm{P}<0,05)$ (Bảng 6 ).

Bảng 6. Mức độ phù hợp của mô hình nghiên cứu cấu trúc

\begin{tabular}{llrrrrl}
\hline Mối quan hệ & Giả thuyết & Es chuẩn hóa & SE & CR & P & $\begin{array}{l}\text { Kết quả giả } \\
\text { thuyết }\end{array}$ \\
\hline CA $\rightarrow$ PS & H1 & 0,270 & 0,074 & 3,010 & $* * *$ & Chấp nhận \\
AA $\rightarrow$ PS & H2 & 0,206 & 0,083 & 2,872 & 0.003 & Chấp nhận \\
PS $\rightarrow$ ERB & H3 & 0,202 & 0,047 & 3,087 & $* * *$ & Chấp nhận \\
\hline
\end{tabular}

Es: Giá trị ước lượng; SE: Sai lệch chuẩn; CR: Giá trị tới hạn; P: Mức ý nghĩa 


\subsection{Thảo luận}

Nghiên cứu được thực hiện nhằm mục đích kiểm tra mối quan hệ giữa mức độ hấp dẫn của điểm đến, sự hài lòng với điểm đến và hành vi có trách nhiệm với môi trường của khách du lịch tại điểm đến Đà Nẵng. Kết quả nghiên cứu cho thấy các giả thuyết đưa ra về các mối quan hệ này được chấp nhận. Theo đó, có sự tác động tích giữa sự hấp dẫn của điểm đến, cụ thể là các thuộc tính cốt lõi và thuộc tính bổ sung, tới sự hài lòng của du khách với điểm đến Đà Nẵng, đồng thời, sự hài lòng của du khách với các điểm du lịch của thành phố sẽ góp phần nâng cao ý thức có trách nhiệm với môi trường của khách du lịch khi tới đây tham quan.

Nhiều nghiên cứu trước đây chỉ ra rằng, việc xác định các thuộc tính thúc đẩy được động lực đi du lịch của khách du lịch sẽ góp phần nâng cao sự hài lòng và được xem là chìa khóa thành công của điểm đến du lịch (Devesa et al., 2010). Ngoài ra, trong nghiên cứu của Stedman (2002), Williams and Soutar (2009) và Chiu et al. (2014) khẳng định rằng khi khách du lịch hài lòng với chuyến tham quan tại một điểm đến du lịch, họ sẽ hiểu rõ hơn về tầm quan trọng của môi trường, từ đó có thể giúp thúc đẩy hành vi có trách nhiệm với môi trường. Kết quả nghiên cứu này một lần nữa khẳng định được sự tác động của sự hấp dẫn của điểm đến, cụ thể của thuộc tính cốt lõi và thuộc tính bổ sung tới sự hài lòng tại đó, từ đó, tác động tích cực tới hành vi có trách nhiệm với môi trường của khách du lịch.

\section{KẾT LUẬN}

Nghiên cứu có những đóng góp về mặt lý thuyết và thực tiễn trong việc nghiên cứu hành vi có trách nhiệm với môi trường của khách du lịch tại điểm đến, cụ thể:

Về mặt lý thuyết, nghiên cứu là một minh chứng để hiểu về các nhân tố ảnh hưởng đến hành vi có trách nhiệm với môi trường của du khách tại điểm đến du lịch; góp phần khẳng định sự hấp dẫn của điểm đến là nhân tố quan trọng ảnh hưởng đến sự hài lòng với điểm đến và từ đó tác động tích cực tới hành vi có trách nhiệm với môi trường của du khách. Đối với các nghiên cứu liên quan đến chủ đề, đây sẽ là nguồn tham khảo để xây dựng các mô hình nghiên cứu tại các điểm du lịch khác.

Về mặt thực tiến, du lịch là hoạt động kinh tế quan trọng đối với sự phát triển của thành phố Đà Nẵng nhưng sự phát triển của du lịch cũng gây ra những tác động tiêu cực tới môi trường. Do đó, du lịch bền vững là lựa chọn cho định hướng phát triển của thành phố. Các cơ quan quản lý đang ngày càng xem trọng vấn đề bảo vệ môi trường của điểm đến du lịch. Việc hiểu được hành vi có trách nhiệm với môi trường của khách du lịch góp phần hỗ trợ đưa ra các giải pháp phát triển phù hợp. Kết quả nghiên cứu là nguồn tư liệu tham khảo cho các nhà quản lý trong việc thực hiện các chiến lược phát triển bằng cách quan tâm đến quan điểm và ý kiến của khách du lịch khi họ viếng thăm thành phố Đà Nẵng. Để nâng cao hành vi có trách nhiệm với môi trường của khách du lịch, các nhà quản lý nên quan tâm đến những trải nghiệm mang tới sự hài lòng của khách du lịch thông qua việc chú trọng khai thác hợp lý các giá trị tài nguyên du lịch để tạo ra các điểm du lịch với những dịch vụ tham quan và giải trí hấp dẫn, đồng thời, nâng cao chất lượng của các dịch vụ cung ứng phục vụ du lịch để mang đến sự thoải mái cho khách du lịch, từ đó, góp phần thúc đẩy những hành vi tích cực của khách du lịch tại điểm đến Đà Nẵng.

Nghiên cứu có những hạn chế cần được giải quyết trong tương lại, cụ thể:

Thứ nhất, nghiên cứu đánh giá chung về các địa điểm du lịch trên thành phố Đà Nẵng. Vì vậy, có thể chưa đi sâu phân tích được sự hài lòng của khách du lịch với từng điểm du lịch khác nhau như điểm du lịch tự nhiên, điểm du lịch văn hóa, tâm linh ...cũng như hành vi có trách nhiệm đối với môi trường của du khách ở từng địa điểm. Do đó, các nghiên cứu trong tương lai có thể đánh giá riêng lẻ tại các điểm du lịch để xác định xem có sự khác biệt về sự hài lòng cũng như hành vi có trách nhiệm với môi trường của du khách.

Thư hai, nghiên cứu có hạn chế trong việc thu thập số liệu. Do tác động của dịch Covid-19, lượng khách du lịch tới Đà Nẵng ít, chỉ có khách nội địa. Điều này dẫn tới các đáp viên quốc tế không tham gia vào việc khảo sát này. Vì vậy, mẫu nghiên cứu có thể chưa phản ánh tốt nhất mục đích nghiên cứu. Những nghiên cứu sau nên thực hiện vào thời điểm có khách du lịch quốc tế tham quan để kiểm định tác động của sự gắn bó với địa điểm của khách du lịch, sự hấp dẫn của điểm đến về sự hài lòng và từ đó, tới hành vi có trách nhiệm với môi trường.

\section{TÀI LIỆU THAM KHẢO}

Akama, J. S., \& Kieti, D. M. (2003). Measuring tourist satisfaction with Kenya's wildlife safari: A case study of Tsavo West National Park. Tourism Management, 24(1), 73-81.

Albayrak, T., \& Caber, M. (2013). The symmetric and asymmetric influences of destination attributes on overall visitor satisfaction. Current Issues in Tourism, 16(2), 149-166. 
Andersson, T. D., \& Getz, D. (2009). Tourism as a mixed industry: Differences between private, public and not-for-profit festivals. Tourism Management, 30(6), 847-856.

Barnes, S. J., Mattsson, J., \& Sørensen, F. (2014). Destination brand experience and visitor behavior: Testing a scale in the tourism context. Annals of Tourism Research, 48, 121-139.

Benckendorff, P. J., \& Pearce, P. L. (2003). Australian tourist attractions: The links between organizational characteristics and planning. Journal of Travel Research, 42(1), 24-35.

Cheng, T. M., C. Wu, H., \& Huang, L. M. (2013). The influence of place attachment on the relationship between destination attractiveness and environmentally responsible behavior for island tourism in Penghu, Taiwan. Journal of Sustainable Tourism, 21(8), 1166-1187.

Chi, C. G. Q., \& Qu, H. (2008). Examining the structural relationships of destination image, tourist satisfaction and destination loyalty: An integrated approach. Tourism Management, 29(4), 624-636.

Chiu, Y. T. H., Lee, W. I., \& Chen, T. H. (2014). Environmentally responsible behavior in ecotourism: Antecedents and implications. Tourism Management, 40, 321-329. https://doi.org/10.1016/j.tourman.2013.06.013

Cholik, D. M. A. (2017) \& Se, M. (2017). The development of tourism industry in Indonesia: Current problems and challenges. European Journal of Research and Reflection in Management Sciences, 5(1), 49-59.

Coghlan, A. (2012). Linking natural resource management to tourist satisfaction: A study of Australia's Great Barrier Reef. Journal of Sustainable Tourism, 20(1), 41-58.

Davis, J. L., Le, B., \& Coy, A. E. (2011). Building a model of commitment to the natural environment to predict ecological behavior and willingness to sacrifice. Journal of Environmental Psychology, 31(3), 257-265.

Devesa, M., Laguna, M., \& Palacios, A. (2010). The role of motivation in visitor satisfaction: Empirical evidence in rural tourism. Tourism Management, 31(4), 547-552.

Dolnicar, S., \& Leisch, F. (2008). An investigation of tourists' patterns of obligation to protect the environment. Journal of Travel Research, 46(4), 381-391.

Funk, D. C., Ridinger, L. L., \& Moorman, A. M. (2004). Exploring origins of involvement: Understanding the relationship between consumer motives and involvement with professional sport teams. Leisure Sciences, 26(1), 35-61.
Halpenny, E. A. (2010). Pro-environmental behaviours and park visitors: The effect of place attachment. Journal of Environmental Psychology, 30(4), 409-421. https://doi.org/10.1016/j.jenvp.2010.04.006

He, X., Hu, D., Swanson, S. R., Su, L., \& Chen, X. (2018). Destination perceptions, relationship quality, and tourist environmentally responsible behavior. Tourism Management Perspectives, 28, 93-104. https://doi.org/10.1016/j.tmp.2018.08.001

Hosany, S., \& Prayag, G. (2013). Patterns of tourists' emotional responses, satisfaction, and intention to recommend. Journal of Business Research, 66(6), 730-737.

Hou, J. S., Lin, C. H., \& Morais, D. B. (2005). Antecedents of attachment to a cultural tourism destination: The case of Hakka and non-Hakka Taiwanese visitors to Pei-Pu, Taiwan. Journal of Travel Research, 44(2), 221-233.

Hu, W., \& Wall, G. (2005). Environmental management, environmental image and the competitive tourist attraction. Journal of Sustainable Tourism, 13(6), 617-635.

Hu, Y., \& Ritchie, J. B. (1993). Measuring destination attractiveness: A contextual approach. Journal of Travel Research, 32(2), 25-34.

Krešić, D., \& Prebežac, D. (2011). Index of destination attractiveness as a tool for destination attractiveness assessment. Tourism: An International Interdisciplinary Journal, 59(4), 497-517.

Lai, W. T., \& Chen, C. F. (2011). Behavioral intentions of public transit passengers-The roles of service quality, perceived value, satisfaction and involvement. Transport Policy, 18(2), 318-325.

Leask, A. (2010). Progress in visitor attraction research: Towards more effective management. Tourism Management, 31(2), 155-166.

Lee, T. H., Jan, F. H., \& Yang, C.-C. (2013). Conceptualizing and measuring environmentally responsible behaviors from the perspective of community-based tourists. Tourism Management, 36, 454-468. https://doi.org/10.1016/j.tourman.2012.09.012

Lyon, A., Hunter, J. P., \& Warnaby, G. (2017). Are we any closer to sustainable development? Listening to active stakeholder discourses of tourism development in the Waterberg Biosphere Reserve, South Africa. Tourism Management, 61, 234-247.

Mohammed, N., Aziz, Y. A., Awang, K. W., \& Samdin, Z. (2018). Influence of destination attractiveness on place satisfaction and environmentally responsible behavior in Marine 
Parks. Journal of Sustainability Science and Management, 5, 52-67.

Parola, F., Satta, G., Penco, L., \& Persico, L. (2014). Destination satisfaction and cruiser behaviour: The moderating effect of excursion package. Research in Transportation Business \& Management, 13, 53-64.

Ramkissoon, H., Weiler, B., \& Smith, L. D. G. (2012). Place attachment and pro-environmental behaviour in national parks: The development of a conceptual framework. Journal of Sustainable Tourism, 20(2), 257-276.

Romão, J., Neuts, B., Nijkamp, P., \& Shikida, A. (2014). Determinants of trip choice, satisfaction and loyalty in an eco-tourism destination: A modelling study on the Shiretoko Peninsula, Japan. Ecological Economics, 107, 195-205.

Sofield, T. H. (2006). Border tourism and border communities: An overview. Tourism Geographies, 8(2), 102-121.

Stedman, R. C. (2002). Toward a social psychology of place: Predicting behavior from place-based cognitions, attitude, and identity. Environment and Behavior, 34(5), 561-581.

Steg, L., \& Vlek, C. (2009). Encouraging proenvironmental behaviour: An integrative review and research agenda. Journal of Environmental Psychology, 29(3), 309-317.

Su, L., \& Hsu, M. K. (2013). Service fairness, consumption emotions, satisfaction, and behavioral intentions: The experience of Chinese heritage tourists. Journal of Travel \& Tourism Marketing, 30(8), 786-805.

Su, L., Hsu, M. K., \& Swanson, S. (2017). The effect of tourist relationship perception on destination loyalty at a world heritage site in China: The mediating role of overall destination satisfaction and trust. Journal of Hospitality \& Tourism Research, 41(2), 180-210.

$\mathrm{Su}$, L., \& Swanson, S. R. (2017). The effect of destination social responsibility on tourist environmentally responsible behavior: Compared analysis of first-time and repeat tourists. Tourism Management, 60, 308-321.

Su, L., Swanson, S. R., \& Chen, X. (2018). Reputation, subjective well-being, and environmental responsibility: The role of satisfaction and identification. Journal of Sustainable Tourism, 26(8), 1344-1361.

Veasna, S., Wu, W. Y., \& Huang, C.-H. (2013). The impact of destination source credibility on destination satisfaction: The mediating effects of destination attachment and destination image. Tourism Management, 36, 511-526.

Williams, P., \& Soutar, G. N. (2009). Value, satisfaction and behavioral intentions in an adventure tourism context. Annals of Tourism Research, 36(3), 413-438. 